INTERNATIONAL DESIGN CONFERENCE - DESIGN 2018

https://doi.org/10.21278/idc.2018.0260

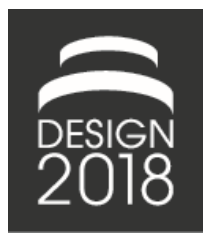

\title{
MATURITY MODEL-BASED PLANNING OF CYBER-PHYSICAL SYSTEMS IN THE MACHINERY AND PLANT ENGINEERING INDUSTRY
}

\author{
T. Westermann and R. Dumitrescu
}

\begin{abstract}
Cyber-physical systems (CPS) are networked, intelligent technical systems that interact with the physical and digital world alike. Companies now increasingly face the challenge of rapidly and consistently exploiting the emerging opportunities of this development. A prerequisite for this is a clear picture of the current position of products, the target position and first concrete steps towards the target projection. The contribution at hand shows an approach for the maturity model-based planning of cyberphysical systems in the machinery and plant engineering industry.
\end{abstract}

Keywords: cyber physical systems, systems engineering (SE), maturity model, innovation management

\section{Introduction}

Due to the development of information and communication technology, products of the machinery and plant engineering industry and related sectors move from mechatronic systems towards cyber-physical systems (CPS). CPS are networked, intelligent technical systems that interact with the physical and digital world alike (Geisberger and Broy, 2012). In industrial production, CPS are e.g. connected machines, storage systems or equipment which exchange information, trigger actions and control themselves autonomously. For the so-called fourth industrial revolution (Industry 4.0), a term which stands for a new step of organizing and controlling the entire value chain, CPS are an important technological basis (acatech, 2011). The change of industrial production affects manufacturing companies (lead market) as well as providers of production technology (lead provider) like the mechanical engineering industry. Due to the increasing permeation with information and communication technology (ICT), classical mechanical engineering products (e.g. machine tools or food processing machines) develop from mechatronic systems into cyber-physical systems. Companies now increasingly face the challenge of rapidly and consistently exploiting the emerging opportunities of this development. A prerequisite for this is a clear picture of the current position of products, the target position and first concrete steps towards the target projection.

The contribution at hand shows an approach for the maturity model-based planning of cyber-physical systems in the machinery and plant engineering industry. The core of this approach is a maturity model for CPS. It defines the characteristics of CPS for different maturity levels, describes their correlations, and provides a systematic approach for the performance assessment and enhancement of their products.

\section{Cyber-physical systems in the machinery and plant engineering industry}

Cyber-Physical Systems are networked, intelligent technical systems that capture, process, and interpret physical data, use services available worldwide, act directly on physical processes, and have multimodal 
human-machine-interfaces (Lee, 2008; Broy, 2010). The term CPS was coined by Gill in 2006, describing the integration of software components ("cyber") into physical, biological or technical systems ("physical") (Lee and Seshia, 2015). The reference architecture for cyber-physical systems in Figure 1 illustrates the basic structure and the principal mode of action of CPS. Typically, CPS consist of a basic physical system (e.g. mechanical structure). By using sensors, they are able to directly record physical data and interact with actuators on physical processes. CPS provide information processing to evaluate, store, and interact actively or reactively with the physical and digital world alike. Through the communication system they can communicate with other systems, both wireless and wired, both locally and globally. Furthermore, CPS use data and services available worldwide (Kagermann et al., 2013). By means of a range of multimodal human-machine-interfaces (HMI) they are able to communicate with users (Geisberger and Broy, 2012).

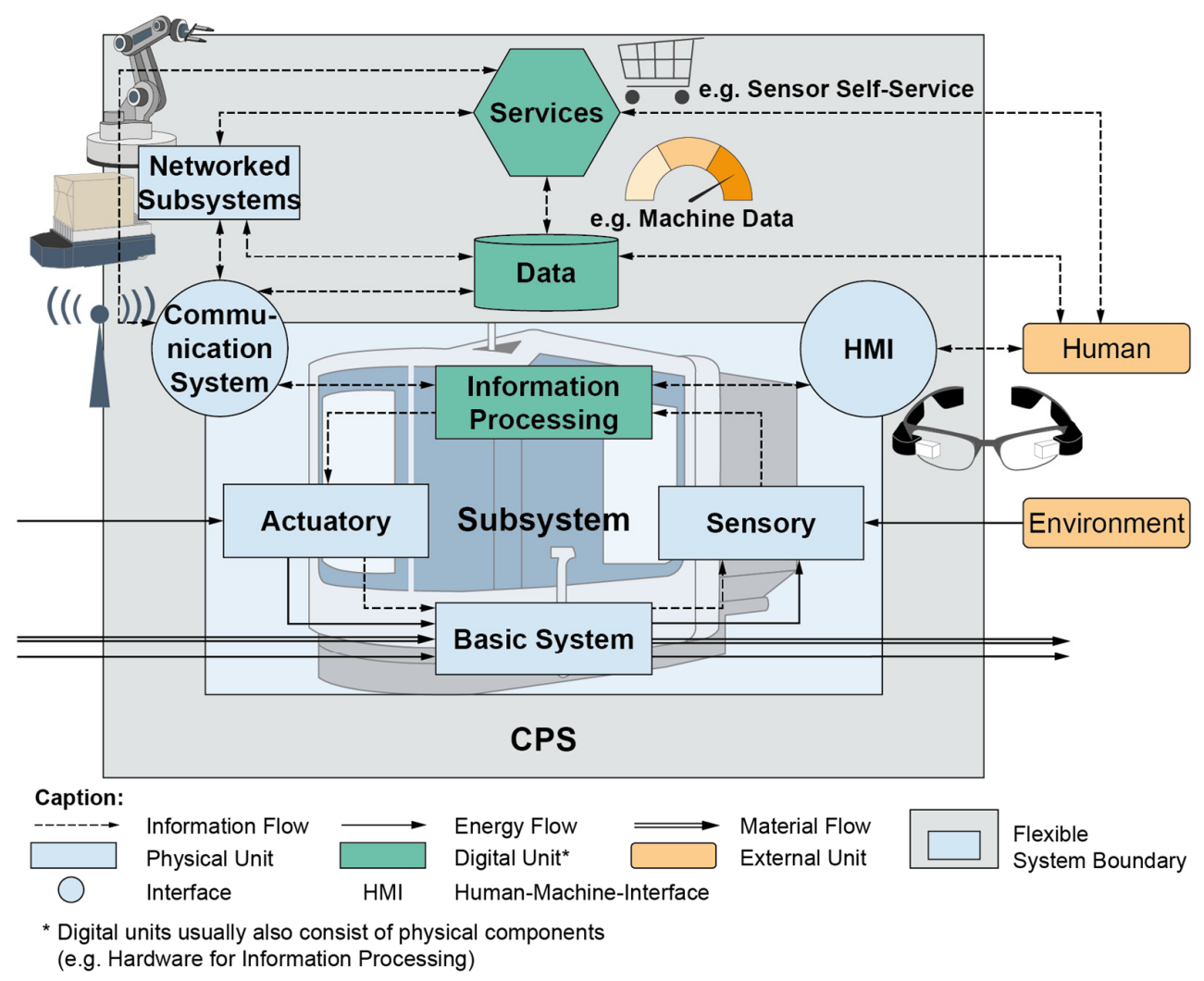

Figure 1. Reference architecture for cyber-physical systems (Westermann, 2017)

The ability to communicate and collaborate with other systems creates networked systems whose functionality and performance exceeds that of the sum of individual systems. The system network is able to flexibly change the roles of the individual systems and their networking as well as to adapt to changing conditions. The networked system, which is increasingly acting in a global dimension, will no longer be controllable exclusively through global governance, but rather, local strategies will need to achieve good behavior on a global scale (Dumitrescu, 2011; Gausemeier et al., 2013).

Cyber-physical systems in production are e.g. networked machines, storage systems or equipment that exchange information independently, initiate actions and control themselves independently. CPS creates socalled smart factories where people, machines, plants, logistics and products communicate and cooperate with each other (Plattform Industrie 4.0, 2016). Beyond the networking of all processes within a company, cross-company networking also takes place. All companies involved in value creation form a value network that can flexibly adapt to changes in the market or in the supply chain (acatech, 2011). Industry 4.0 is the term that describes these changes and CPS are the technical basis that will support their implementation. Industry 4.0 affects both manufacturing companies and the equipment industry. German machine and plant manufacturers are regarded as leading factory equipment suppliers and global technology leaders 
in production technology (Kagermann et al., 2013). In order to maintain or even expand their leadership position, companies must take advantage of the rapid development of ICT and develop their products into cyber-physical systems. However, not only the technical systems will change, but the entire market performance of the companies. Whereas the range of services in the field of mechanical and plant engineering traditionally consists of a combination of material and product-related services, CPS now opens up considerable opportunities to further develop the historically evolved market services into innovative product-service-systems (Emmrich et al., 2015). These potentials for change are based, for example, on the storage and analysis of data, increasing intelligence and networking or digital customer access (Bloching et al., 2015). For providers of CPS, services based on data (so-called digital services) may become an important differentiator in the future as the actual machine will contribute less and less to the generation of the overall solution (Emmrich et al., 2015).

However, the conversion of technical systems is not carried out ad-hoc and uniformly for all systems in the same way. Rather, systems will change in the course of a step-by-step transformation, which will gradually proceed across different performance levels. In doing so, the benefits, especially for new or changed market services, are not only revealed with the highest degree of maturity, but also along all levels of performance. In order to successfully develop their systems further, companies in the mechanical and plant engineering industry need to address the following fields of action (see Figure 2): 1) Objective performance assessment of their systems; 2) Company-specific target definition; 3 ) Systematic performance improvement.

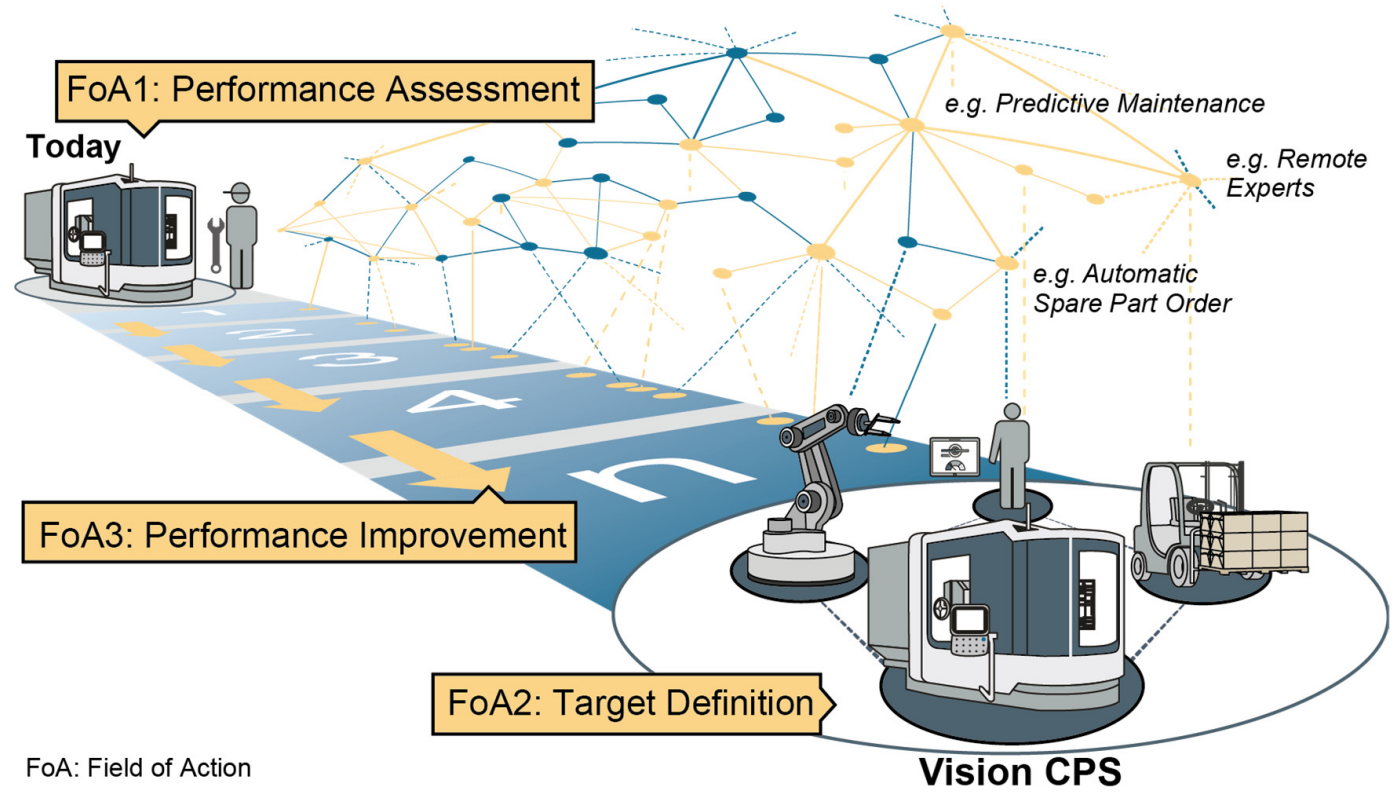

Figure 2. Fields of action for performance evaluation and enhancement of CPS (according to Westermann, 2017)

Using a maturity model is a promising approach to a structured performance improvement. Therefore, the following chapter examines existing maturity models for their suitability for cyber-physical system performance evaluation and enhancement.

\section{Maturity models - status quo}

Key elements of the improvement of objects are an objective evaluation of the performance and on this basis a systematic performance improvement. This is exactly what maturity models are aiming for. In recent decades, a large number of different maturity models with different objects of observation such as processes or organizations have emerged (Akkasoglu, 2013). Prominent examples of maturity models are QMMG, the EFQM Excellence model for quality management, CMMI and SPICE for product and software development processes or PEMM for improving business processes. Depending on the objective 
of the maturity model, the aspect of performance evaluation and enhancement is different. Some maturity models dispense with measures to increase performance and leave it in the assessment of performance. Other models aim for benchmarking against in-house or external objects (de Bruin et al., 2005; Pöppelbuß and Röglinger, 2011). The maturity models focus on different types of processes, but none focusses on technical systems. In the recent past, various maturity models have been developed for various types of technical systems (e.g. smart products or embedded devices). Examples of such models are the "5C architecture for the implementation of CPS" according to Lee and Seshia (2015), The "Intelligent Object Capability Levels" according to Pérez Hernández and Reiff-Marganiec (2014), the "Toolbox Industry 4.0 (Product)" according to Anderl and Fleischer (2015), "Descriptive features and characteristic features of intelligent objects in production and logistics" according to Deindl (2013), "Abilities of intelligent, networked systems" according to Porter and Heppelmann (2014), the "Industrie 4.0 readiness model" according to Lichtblau et al. (2015), "The classification framework for embedded devices" according to Diekmann and Hagenhoff (2006) or PTC's Connected Product Maturity Model (2015). However, none of the mentioned maturity models addresses all the characteristics of cyber-physical systems. In addition, there is a lack of help to determine a company's individual degree of maturity and to develop a concept for increasing performance. Against this background, a maturity model for cyber-physical systems is required.

\section{Approach for the maturity model-based planning of cyber-physical systems}

The maturity model for cyber-physical systems is used to objectively evaluate the performance of existing technical systems, to determine a company-specific target position and to systematically plan an incremental performance improvement. To do this, it defines the characteristics of a CPS for different maturity levels, describes their relationships and the development from low to high maturity. The CPS maturity model is based on the intrinsic features of maturity models for performance evaluation and enhancement according to Christiansen (2009) and consists of performance evaluation, target definition and performance enhancement (see Figure 3). The individual areas contain different phases which include aids and calculation rules. These ensure that the application of the maturity model leads to clear, comparable and reproducible results.

The individual areas of the maturity model are illustrated below by the example of a separator. A separator is an industrial centrifuge for mechanical separation of different phases with different densities, e.g. solids from liquids. The application areas range from separation processes in the chemical and pharmaceutical industry, oil and fat production, to the production of dairy products, beer, wine, fruit and vegetable juices or the processing of mineral oil and petroleum products.

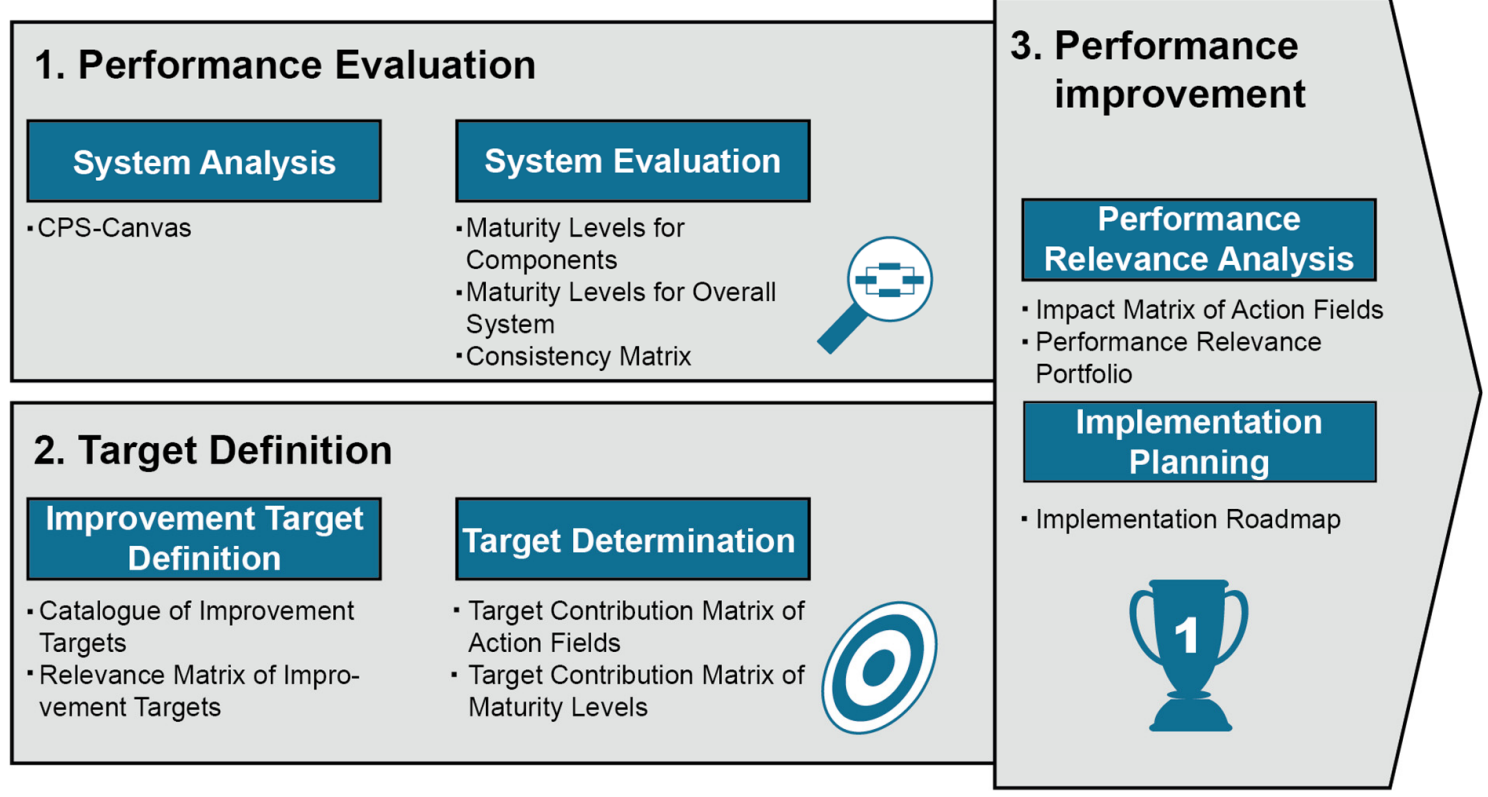

Figure 3. Structure of the maturity model for cyber-physical systems (Westermann, 2017) 


\subsection{Performance evaluation}

The area of performance evaluation serves to objectively assess the current performance of existing technical systems. For this purpose, the two phases of system analysis and system evaluation must be completed. As part of the system analysis, the object of observation is determined and examined. An essential aid in system analysis is the so-called CPS-Canvas (see Figure 4).

\begin{tabular}{|c|c|c|}
\hline Basic System & Information Processing & Networked Subsystems \\
\hline $\begin{array}{l}\text { What is the physical } \\
\text { basic system? }\end{array}$ & $\begin{array}{l}\text { What are the options for the } \\
\text { subsystem to process } \\
\text { information? }\end{array}$ & $\begin{array}{l}\text { Which other systems does the } \\
\text { subsystem interact with? }\end{array}$ \\
\hline e.g. Separator & e.g. Industrial-PC & $\begin{array}{l}\text { e.g. Manufacturing } \\
\text { Exectution Systems }\end{array}$ \\
\hline Sensory & Communication & Data \\
\hline $\begin{array}{l}\text { Which sensors for the acqui- } \\
\text { sition of physical quantities } \\
\text { does the subsystem have? }\end{array}$ & $\begin{array}{l}\text { Which interfaces does the } \\
\text { system have for communicating } \\
\text { with other systems? }\end{array}$ & $\begin{array}{l}\text { Which other systems does the } \\
\text { subsystem interact with? }\end{array}$ \\
\hline $\begin{array}{l}\text { e.g. Vibration } \\
\text { Sensors }\end{array}$ & e.g. Industrial Ethernet & e.g. Operating Data \\
\hline Actuatory & Human-Machine-Interface & Services \\
\hline $\begin{array}{l}\text { Which actuators does the } \\
\text { subsystem have to influence } \\
\text { physical processes? }\end{array}$ & $\begin{array}{l}\text { Which human-machine-inter- } \\
\text { faces does the subsystem } \\
\text { have? }\end{array}$ & $\begin{array}{l}\text { Are there services in the con- } \\
\text { text of the subsystem that are } \\
\text { based on the collection and } \\
\text { interpretation of data? }\end{array}$ \\
\hline e.g. Drives, Valves & e.g. Touchscreen & e.g. Condition Monitoring \\
\hline
\end{tabular}

Figure 4. CPS-Canvas for system analysis (Westermann, 2017)

It provides a framework for uniformly documenting the relevant characteristics of cyber-physical systems. The individual fields are based on the components of the CPS reference architecture in Figure 1. By answering the questions, companies can analyse their system efficiently and present the results transparently. Exemplary answers for the separator include e.g. vibration and turbidity sensors in the field of sensors, drives and valves in the area of actuators, Industrial-PCs (IPC) for information processing or touchscreens as human-machine-interfaces.

Subsequently, the system evaluation takes place. Two maturity level models serve this purpose, one at the component level and one at the overall system level. The component maturity model defines several action fields for every CPS component, with five performance levels each. Figure 5 shows an example of the action elements for the communication system.

These include vertical integration, horizontal integration, connectivity, network connection, and security. The maturity levels now indicate which characteristics each action field can assume. The higher the performance level, the more highly developed the action element is. For example, the levels of connectivity range from level 1 "No Interfaces" to level 5 "Wireless Communication". The separator has the performance level 4 "Connectivity via Industrial Ethernet-Interfaces" in the action element of connectivity but does not currently have wireless communication. The classification into the performance levels is based on the CPS-Canvas. A consistency matrix checks a meaningful classification by excluding inconsistent maturity levels. For example, the system may not have access to the internet (network connection) if it has no interfaces (connectivity). 


\begin{tabular}{|c|c|c|c|c|c|c|}
\hline \multirow{2}{*}{$\begin{array}{c}\text { CPS } \\
\text { Components }\end{array}$} & \multirow{2}{*}{$\begin{array}{l}\text { Action } \\
\text { Fields } \\
\end{array}$} & \multicolumn{5}{|c|}{ Maturity Levels } \\
\hline & & 1 & 2 & 3 & 4 & 5 \\
\hline \multirow{5}{*}{$\begin{array}{c}\text { Communication } \\
\text { System }\end{array}$} & $\begin{array}{c}\text { Vertical } \\
\text { Integration }\end{array}$ & $\begin{array}{l}\text { No vertical } \\
\text { integration }\end{array}$ & $\begin{array}{c}\text { Rudimentary } \\
\text { vertical } \\
\text { integration }\end{array}$ & $\begin{array}{c}\text { Partial } \\
\text { vertical } \\
\text { Integration }\end{array}$ & $\begin{array}{c}\text { Comprehensive } \\
\text { vertical } \\
\text { integration }\end{array}$ & $\begin{array}{l}\text { Consistent } \\
\text { vertical } \\
\text { integration }\end{array}$ \\
\hline & $\begin{array}{l}\text { Horizontal } \\
\text { Integration }\end{array}$ & $\begin{array}{l}\text { No horizontal } \\
\text { integration }\end{array}$ & $\begin{array}{c}\text { Rudimentary } \\
\text { horizontal } \\
\text { integration }\end{array}$ & $\begin{array}{c}\text { Partial } \\
\text { horizontal } \\
\text { integration }\end{array}$ & $\begin{array}{c}\text { Comprehensive } \\
\text { horizontal } \\
\text { Integration }\end{array}$ & $\begin{array}{l}\text { Consistent } \\
\text { horizontal } \\
\text { Integration }\end{array}$ \\
\hline & Connectivity & $\begin{array}{c}\text { No } \\
\text { interfaces }\end{array}$ & $\begin{array}{l}\text { Send and } \\
\text { recieve of } \\
\text { I/O-Signals }\end{array}$ & $\begin{array}{l}\text { Connectivity } \\
\text { via Fieldbus- } \\
\text { Interfaces }\end{array}$ & $\begin{array}{l}\text { Connectivity via } \\
\text { Industrial Ether- } \\
\text { net-Interfaces }\end{array}$ & $\begin{array}{c}\text { Wireless } \\
\text { Communication }\end{array}$ \\
\hline & $\begin{array}{c}\text { Network } \\
\text { Connection }\end{array}$ & $\begin{array}{c}\text { No } \\
\text { network } \\
\text { connection }\end{array}$ & $\begin{array}{l}\text { Point-to-point } \\
\text { connection }\end{array}$ & $\begin{array}{l}\text { Integration into } \\
\text { local networks }\end{array}$ & $\begin{array}{l}\text { Integration into } \\
\text { global networks }\end{array}$ & $\begin{array}{l}\text { Access to } \\
\text { the internet }\end{array}$ \\
\hline & Security & $\begin{array}{l}\text { Unencrypted } \\
\text { communication }\end{array}$ & $\begin{array}{c}\text { Authenticated / } \\
\text { authorized } \\
\text { connections }\end{array}$ & $\begin{array}{c}\text { Secure } \\
\text { Interfaces }\end{array}$ & $\begin{array}{l}\text { Encrypted } \\
\text { communication }\end{array}$ & $\begin{array}{c}\text { Most modern } \\
\text { communication } \\
\text { standards }\end{array}$ \\
\hline
\end{tabular}

Figure 5. Maturity levels for components at the example of the communication system (Westermann, 2017)

In addition to the performance levels at the component level, the CPS maturity model provides a performance level model for the overall system (see Figure 6). It defines five maturity levels for the performance of the entire CPS. The skills range from the "Monitoring" level to the "Cooperation" level. At the first performance level, the CPS is able to collect, process and store comprehensive physical data of the subsystem, the product and the environment for tracing. With higher levels of performance, the capabilities of the CPS increase until it is finally able to negotiate behavior with globally networked and cooperating systems, taking into account the goals of the overall system. The maturity levels of the overall system are linked to the performance levels of all CPS components, so that a component-level assessment automatically provides information about the performance of the overall system. In the case of the separator, performance level 2 "communication and analysis" applies. Currently, the separator is partially networked with other systems and able to analyse real-time data as well as historical data and to make these other systems available. An independent interpretation of the data (performance level 3 "interpretation and services") is not yet possible.

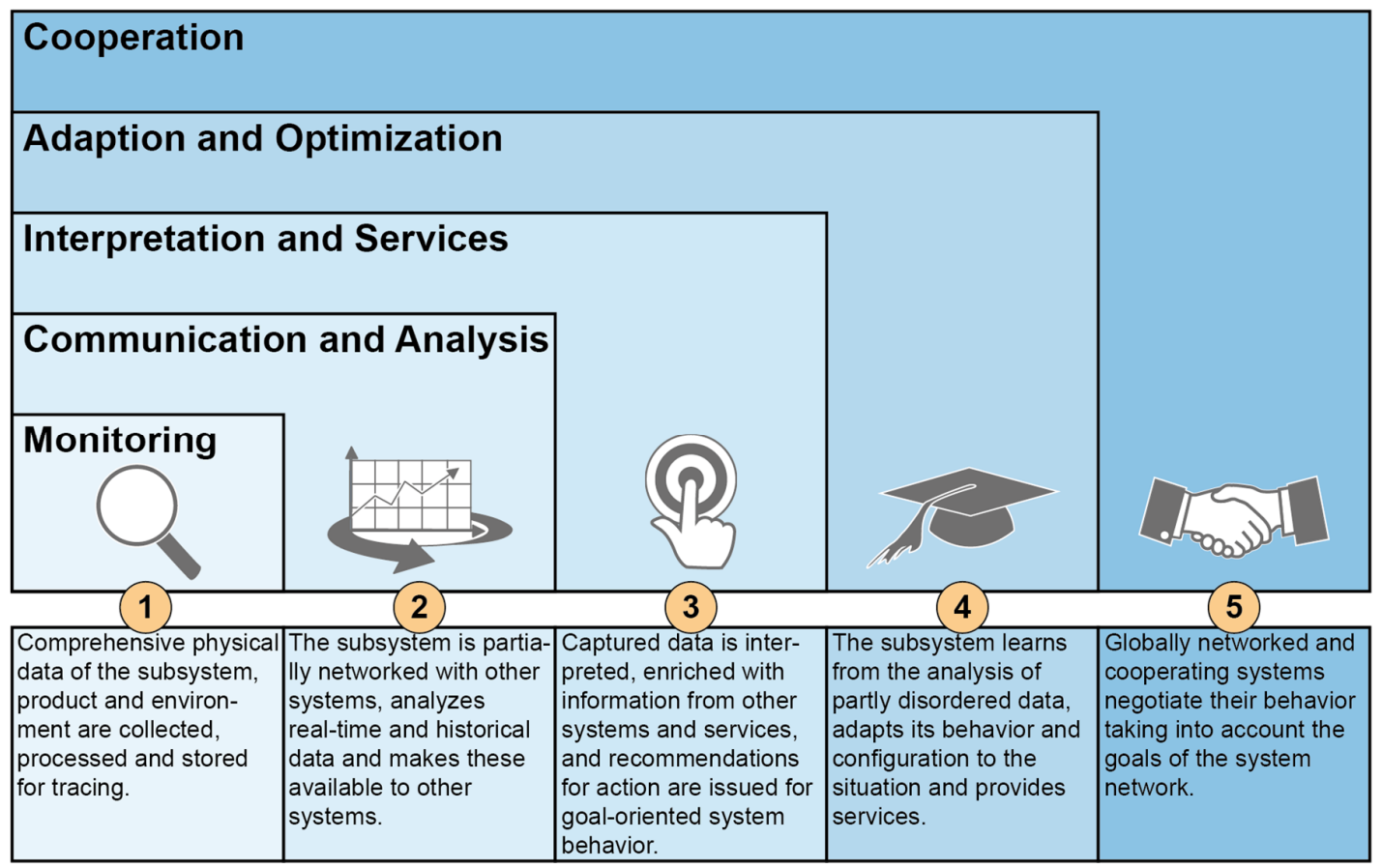

Figure 6. Maturity levels for the overall system (Westermann, 2017) 


\subsection{Target definition}

The purpose of the target definition is the determination of a company-adequate target state for cyberphysical systems. The principle is not to strive for the highest possible maturity level, but to determine a meaningful level for the company. For this purpose, initial improvement goals are determined in the first phase improvement target definition. Improvement goals are concrete intentions pursued by a company with the technical development of its products. Examples of such targets with respect to the separator are e.g. "reduce scrap", "reduce downtime", "increase transparency", or "increase usability". As a support, the CPS maturity model provides a catalogue of improvement goals that are commonly used in the literature in the context of CPS. However, companies may also add their own improvement goals. After selecting the improvement goals, a pairwise comparison of the improvement goals is carried out in a relevance matrix by means of a relevance analysis. The main question is: "Is the improvement goal i (line) more important than the improvement goal $\mathrm{j}$ (column)?". From the evaluations of the relevance matrix stems the relevance sum (row sum), out of which a sequence of relevance can be formed. The ascertained order additionally calculates a so-called rank index that ranges between 1 and 2 . This means that improvement goals with a high relevance are taken into greater consideration, but are not overrated. On the other hand, the low-relevance improvement goals are not undervalued or devalued [Bal04].

After selecting the improvement target, the target determination is made. In this phase a companyspecific maturity level per action field is defined by means of the tools target contribution matrix of the action fields and target contribution matrix of the maturity levels. The target contribution matrix of the action fields is based on the question: "How much does the action fields i (line) contribute to the improvement goal $\mathrm{j}$ (column)?". The contribution can be scored with the numbers 0 to 3 , where " $0=$ no contribution" and " 3 = strong contribution". The action field multi-modality, for example, has no target contribution to the improvement goal "increase transparency", but a strong contribution to the goal "user-friendliness increase". From the matrix results the width effect, the depth effect as well as the target contribution index. The broad effect of an action field indicates the degree to which the action field is influenced by the total of all improvement goals. The depth effect demonstrates how strongly an action element affects the respective improvement goals. The width effect multiplied by the depth effect yields the target contribution index, which states the extent to which the action element contributes to the improvement goals (Balázová, 2004).

The target contribution matrix of the maturity levels now investigates how much the performance level of an action field contributes to the improvement goals. Here the question can be answered with the numbers 0 to 3 per performance level. After the initial filling, the matrix is cleaned up. For each improvement goal, it is checked as of when a higher maturity level of an action field no longer has a stronger contribution to an improvement goal. Thus, only the highest target contributions with the lowest performance level per action field are considered. This is based on the conception that a higher performance level should only be aimed for if it is associated with an increase in the target contribution. The target effect can then be determined from the adjusted target contribution matrix of the performance levels. This indicates how far a performance level affects an improvement goal. To account for the relevance of the improvement goals, the weighted target effect is then formed by multiplying the entries in the matrix by the rank indexes of the improvement goals. A ranking can hence be formed from the weighted target effects. The maturity level with the highest weighted target effect represents the target performance level for the action element. Figure 7 gives an overview of all calculation rules and assigns them to the individual areas of the maturity model.

\begin{tabular}{|c|c|c|c|c|}
\hline $\begin{array}{l}\text { 1. Performance } \\
\text { Evaluation }\end{array}$ & \multicolumn{3}{|c|}{ 2. Target Definition } & 3. Performance \\
\hline Consistency Matrix & $\begin{array}{l}\text { Relevance Matrix of } \\
\text { Improvement } \\
\text { Targets }\end{array}$ & $\begin{array}{l}\text { Target Contribution } \\
\text { Matrix of Action } \\
\text { Fields }\end{array}$ & $\begin{array}{l}\text { Target Contribution } \\
\text { Matrix of Maturity } \\
\text { Levels }\end{array}$ & $\begin{array}{l}\text { Impact Matrix of Action } \\
\text { Fields }\end{array}$ \\
\hline $\begin{array}{l}\text { Can one maturity level } \\
\text { be shared with another } \\
\text { maturity level? }\end{array}$ & $\begin{array}{l}\text { Is one improvement } \\
\text { target more important } \\
\text { than another? }\end{array}$ & $\begin{array}{l}\text { To what extent does } \\
\text { an action field contri- } \\
\text { bute to an improve- } \\
\text { ment target? }\end{array}$ & $\begin{array}{l}\text { To what extent does the } \\
\text { maturity level of the } \\
\text { action field contribute to } \\
\text { an improvement target? }\end{array}$ & $\begin{array}{l}\text { How strongly does an } \\
\text { action field influence } \\
\text { other action fields? }\end{array}$ \\
\hline
\end{tabular}

Figure 7. Overview of calculation rules 


\subsection{Performance improvement}

With the help of the performance improvement it is possible to bridge the gap between current performance and the target maturity level. For this purpose, it is vital to detemine which action elements are addressed in which order as well as to identify the action fields that have a high contribution to the improvement goals and at the same time are strongly interlinked with other action fields. These action fields are highly relevant for the performance of the considered system. In the course of the performance relevance analysis, the mentioned sub-information is summarized into one statement. The already determined target contribution index from the target contribution matrix of the action fields rates an action element's contribution to the improvement goals. The (so far) missing statement about the networking of the action elements among each other is brought about by an impact matrix of the action fields that takes both direct and indirect influences into account. It answers the question "To what extent does the action element $\mathrm{i}$ (line) influence the action field $\mathrm{j}$ (column)?".. The main result of the influence matrix is the so-called crosslinking index, which results from the multiplication of indirect and direct assets. This characteristic value indicates how strongly an action field is interlinked with other action fields. The change of strongly networked action fields is thus likely to have a strong influence on further action fields.

The results of the performance relevance analysis can now be mapped into the performance relevance portfolio shown in Figure 8. The abscissa represents the target contribution index (normalized) and the ordinate the cross-linking index (normalized). Therefore, already first statements about the prioritization of the action fields can be made. Action elements with a high target contribution and a low cross-linking index should be tackled immediately, since they have a high contribution to achieving the goals, but at the same time little interaction with other action elements has to be taken into account. Action fields with a high target contribution and a high cross-linking index need to be worked on long-term, as they are highly relevant to the system's performance. Selected plot elements of the application example separator are shown in Figure 8. The most important element of the action is the type of information processing since it has both a high target contribution, as well as a high index of networking. Lower priority is given to multimodality as an action element of the CPS component HMI.

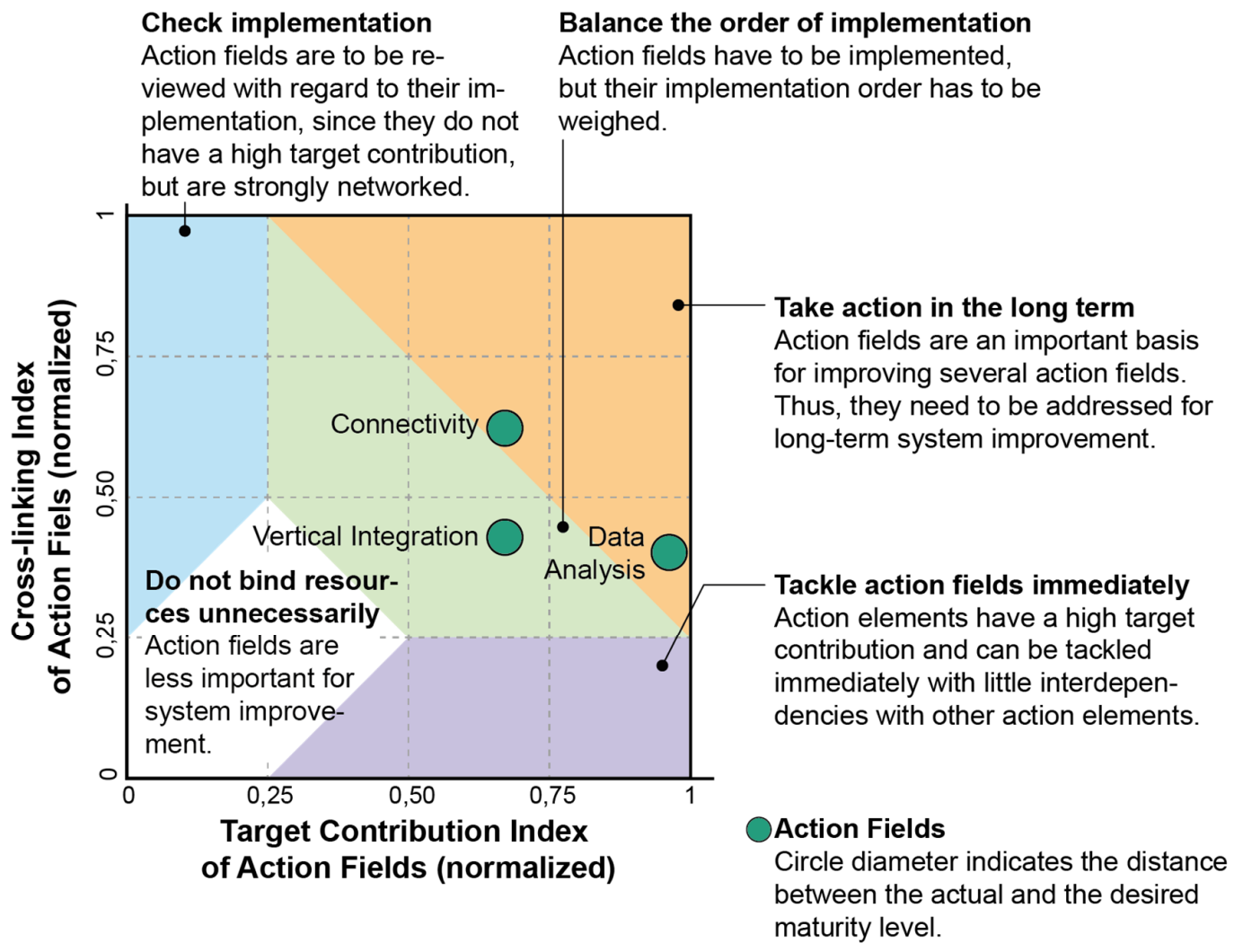

Figure 8. Performance relevance portfolio for prioritization of action fields (Westermann, 2017) 
The performance relevance analysis is followed by the implementation planning where the prioritized action elements are backed up with concrete solutions. It might, for example, be determined here which technical solutions the type of information processing can be improved with. The technical solutions are transformed into an implementation roadmap, which, depending on the prioritization of the action fields, specifies a time sequence for the implementation of the technical solutions.

\subsection{Tool-support}

The web application CPS Maturity Assessment is the software-technical implementation of the maturity model for CPS. It contains the tools and calculation rules and guides the user through the individual areas and phases of the maturity model. All calculations are performed automatically and inputs and analysis results are saved. Due to its implementation as a web application in the cloud, the software can be run independent of location and device. The responsive web design makes it easy to use with mobile devices such as tablet PCs or smartphones. State-of-the-art frameworks and libraries were used in the design of the user interface to enable intuitive operation. Figure 9 shows the web application as a workshop situation.

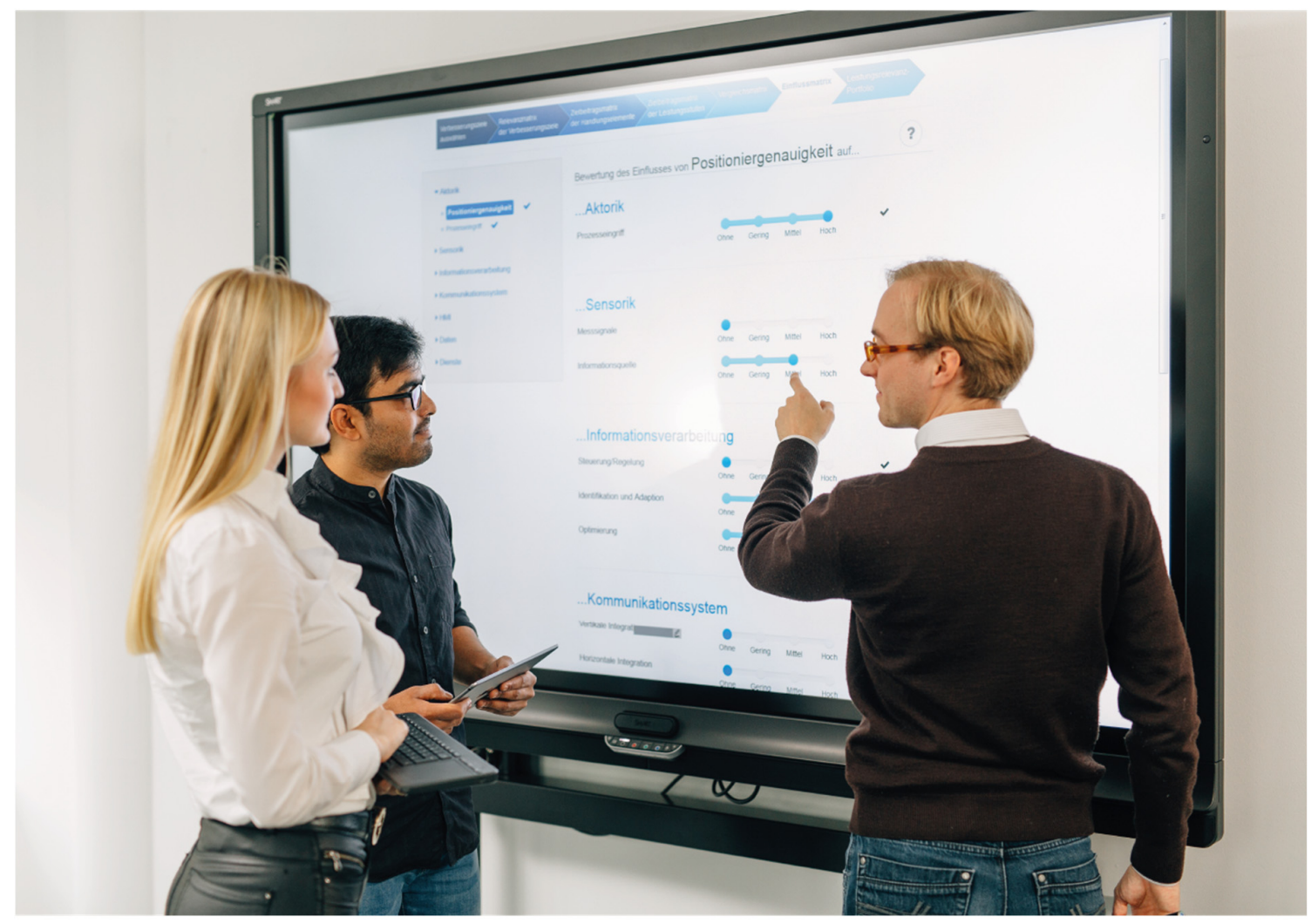

Figure 9. Web application CPS Maturity Assessment in a workshop situation

The user guidance of the software starts with the creation of an account by entering the user name and password. The user can then create a new assessment, whereupon information about the system to be viewed is requested (e. g. product name, product type). If the user wants to continue an assessment that has already been processed, no further information on the object of the investigation is required. User-based authentication ensures that only the assessments performed by the user are displayed. After the system to be considered has been created, the area of performance evaluation begins with the system evaluation phase. Here, the user evaluates the current performance of the system at component level using the performance levels. All CPS components, action fields and performance levels are described in the software according to context. Further explanatory documents are therefore 
not required. During the evaluation, the software automatically checks the plausibility of the entries and warns the user of inconsistent entries. The software uses the information in the consistency matrix for this purpose.

After completion of the performance evaluation, the user is automatically forwarded to the improvement target selection phase of the target definition area. Here the user can select improvement goals from a list or enter their own goals. The formulation and selection of the goals is prioritized by means of the relevance matrix. Based on the performance evaluation and target definition, the software now supports performance relevance analysis in the area of performance improvement. Here, the user first fills in the influence matrix of the action fields. After automatic calculation of the resulting networking indices, the software displays the performance relevance portfolio with the relevant action elements.

The web application CPS Maturity Assessment enables a simple and economical application of the maturity model for CPS. Analysis results are automatically documented and archived. This makes it easier, among other things, to compare several systems or to monitor the progress of system improvement by regularly implementing the maturity model.

\section{Conclusion and outlook}

Due to the increasing permeation of ICT, classical mechanical engineering products are changing from mechatronic systems into cyber-physical systems. In order to maintain or even expand their position as leading factory equipment suppliers and global technology leaders in production technology, German mechanical and plant engineering companies must gradually develop their systems into CPS. Successful object enhancement is based on a neutral assessment of the current performance that can be used to systematically improve performance. Using a maturity model is a promising approach to structured performance enhancement, but existing maturity models tend to target processes and organizations rather than technical systems.

Against this background, a maturity model for cyber-physical systems was developed, which supports companies in planning the gradual development of their products towards cyber-physical systems. The maturity model includes the three main components performance evaluation, target definition and performance improvement. The performance evaluation will provide an objective assessment of the current performance of the system. During the target definition, a company-specific target maturity level, which is based on concrete improvement goals, has to be determined. As part of the performance improvement, the gradual improvement of the system is planned. The individual areas are subdivided into different phases with aids and calculation rules, ensureing that the application of the maturity model leads to clear, comparable and reproducible results. The maturity model was tested on the practical example of a separator.

Currently the maturity model is used in further industrial projects. In addition, continuing research results in tools that assign concrete implementation patterns to the individual performance levels. This allows companies to quickly turn to proven solutions and thus accelerate their performance. In addition, a software tool is created that maps the maturity model for CPS inside the computer and thus simplifies, among other things, the comparison of different systems.

\section{References}

acatech - Akademie der Technikwissenschaften (2011), Cyber-Physical Systems - Innovationsmotor für Mobilität, Gesundheit, Energie und Produktion, Springer, Berlin, Heidelberg.

Akkasoglu, G. (2013), Methodik zur Konzeption und Applikation anwendungsspezifischer Reifegradmodelle unter Berücksichtigung der Informationsunsicherheit, PhD thesis, Technische Fakultät der FriedrichAlexander-Universität Erlangen-Nürnberg.

Anderl, R. and Fleischer, J. (2015), Leitfaden Industrie 4.0 - Orientierungshilfe zur Einführung in den Mittelstand, VDMA Forum Industrie, Frankfurt a. M.

Balázová, M. (2004), Systematik zur reifegradbasierten Leistungsbewertung und -steigerung von Geschäftsprozessen im Mittelstand, $\mathrm{PhD}$ thesis, Faculty of Mechanical Engineering, Paderborn University. 
Bloching, B., Leutiger, P., Oltmanns, T., Rossbach, C., Schlick, T. et al. (2015), Die digitale Transformation der Industrie - Was sie bedeutet. Wer gewinnt. Was jetzt zu tun ist, Roland Berger Strategy Consultants $\mathrm{GmbH}$; BDI Bundesverband der deutschen Industrie e.V.

Broy, M. (2010), Cyber-Physical Systems - Innovation durch Software-intensive eingebettete Systeme, Springer, Berlin, Heidelberg.

Christiansen, S.-K. (2009), Methode zur Klassifikation und Entwicklung reifegradbasierter Leistungsbewertungs- und Leistungssteigerungsmodelle, $\mathrm{PhD}$ thesis, Faculty of Mechanical Engineering, Paderborn University.

de Bruin, T., Freeze, R., Kaulkarni, U. and Rosemann, M. (2005), "Understanding the Main Phases of Developing a Maturity Assessment Model", Australasian Conference on Information Systems (ACIS), Sydney, New South Wales, Australia, November 30 - December 2, 2005.

Deindl, M. (2013), Gestaltung des Einsatzes von intelligenten Objekten in Produktion und Logistik, PhD thesis, Faculty of Mechanical Engineering, RWTH Aachen University.

Diekmann, T. and Hagenhoff, S. (2006), Einsatzgebiete von Ubiquitous Computing-Technologien entlang der betrieblichen Wertschöpfungskette, No. 2/2006, Institut für Wirtschaftsinformatik, Georg-AugustUniversität Göttingen, Göttingen.

Dumitrescu, R. (2011), Entwicklungssystematik zur Integration kognitiver Funktionen in fortgeschrittene mechatronische Systeme, PhD thesis, Faculty of Mechanical Engineering, Paderborn University.

Emmrich, V., Döbele, M., Bauernhansl, T., Paulus-Rohmer, D., Schatz, A. and Weskamp, M. (2015), Geschäftsmodell-Innovationen durch Industrie 4.0 - Chancen und Risiken für den Maschinen- und Anlagenbau, Dr. Wieselhuber \& Parner GmbG/Fraunhofer IPA.

Gausemeier, J., Anacker, H., Czaja, A., Waßmann, H. and Dumitrescu, R. (2013), “Auf dem Weg zu intelligenten technischen Systemen", 9. Paderborner Workshop Entwurf mechatronischer Systeme, April 18-19, 2013, HNI-Verlagsschriftenreihe, Paderborn.

Geisberger, E. and Broy, M. (2012), agendaCPS - Integrierte Forschungsagenda Cyber-Physical Systems, Springer, Berlin, Heidelberg.

Kagermann, H., Riemensperger, F., Hoke, D., Schuh, G., Scheer, A.-W. et al. (2015), Smart Service Welt - Umsetzungsempfehlungen für das Zukunftsprojekt Internetbasierte Dienste für die Wirtschaft, acatech.

Kagermann, H., Wahlster, W. and Helbig, J. (2013), Deutschland Zukunft als Produktionsstandort sichern Umsetzungsempfehlungen für das Zukunftsprojekt Industrie 4.0, Abschlussbericht des Arbeitskreises Industrie 4.0, Forschungs union / acatech.

Lee, E.A. (2008), Cyber Physical Systems: Design Challenges, No. UCB/EECS-2008-8, Electrical Engineering and Computer Sciences, University of California at Berkley, Berkley, USA.

Lee, E.A. and Seshia, S.A. (2015), Introduction to embedded systems - A cyber-physical systems approach, 2nd ed.

Lichtblau, K., Stich, V., Bertenrath, R., Blum, M., Bleider, M. et al. (2015), Industrie 4.0-Readiness, Cologne Institute for Economic Research (IW) Consult GmbH / FIR at RWTH Aachen University, Aachen, Cologne.

Pérez Hernández, M.E. and Reiff-Marganiec, S. (2014), “Classifying Smart Objects using capabilities”, 2014 International Conference on Smart Computing, Hong Kong, China, November 3 - 5, 2014.

Plattform Industrie 4.0 (2016), Was ist Industrie 4.0?. [online] Plattform Industrie 4.0. Available at: http://www.plattform-i40.de/I40/Navigation/DE/Industrie40/WasIndustrie40/was-ist-industrie40.html;jsesio nid=EC02B12B25AB3B25 01183DFEC114FF9D (accessed 10.03.2016)

Pöppelbuß, J. and Röglinger, M. (2011), "What makes a useful Maturity Model? A Framework of General Design Principles for Maturity Models and its Demonstration in Business Process Management", 2011 European Conference on Information Systems (ECIS) Proceedings, Tel Aviv, Israel, June 9-11, 2011.

Porter, M.E. and Heppelmann, J.E. (2014), "Wie smarte Produkte den Wettbewerb verändern", Harvard Business Manager, Vol. 12/2014. 
PTC (2015), Connected Product Maturity Model - Achieve Innovation with Connected Capabilities, White Paper.

VDI Verein Deutscher Ingenieure (2004), VDI 2206 - Entwicklungsmethodik für mechatronische Systeme, Beuth Verlag GmbH, Berlin.

Westermann, T. (2017), Systematik zur Reifegradmodell-basierten Planung von Cyber-Physical Systems des Maschinen- und Anlagenbaus, PhD thesis, Faculty of Mechanical Engineering, Paderborn University.

Dr.-Ing. Thorsten Westermann, Group Manager Product-Service-Systems

Fraunhofer Research Institute for Mechatronic Systems Design IEM, Product Engineering

Zukunftsmeile 1, 33102 Paderborn, Germany

Email: thorsten.westermann@iem.fraunhofer.de 